\title{
MICROGLIA AS POTENTIAL REGULATORS OF EMPATHY AND PROSOCIAL BEHAVIOR - A HYPOTHESIS
}

\author{
Marin D. Zhelezov \\ Department of Anatomy, Histology and Embryology, Medical University, Varna, Bulgaria
}

\begin{abstract}
Microglia are the primary resident mononuclear phagocytes that maintain central nervous system homeostasis under physiological and pathological conditions. Recent evidence has shown that they differ considerably from other macrophages by contributing to pre- and postnatal brain development by controlling processes such as neurogenesis, oligodendrogenesis, progenitor numbers and the generation and elimination of synapses. Here I Dance round a hypothetical microglial role in modulating empathy and prosocial behavior via influencing the development of associated nervous structures, including the ventromedial and dorsolateral prefrontal cortex, anterior cingulate, precuneus, inferior frontal gyrus, insula and striatum. A potential contributing role of microglia in shaping normal interindividual differences in empathetic abilities and related behaviors is also discussed.
\end{abstract}

Biomed Rev 2016, 27: 69-73

Key words: compassion, altruism, empathy, development, synapses, prenatal

\section{INTRODUCTION}

Microglia are the primary resident mononuclear-phagocytes of the central nervous system (CNS) parenchyma. They belong to the glial system of non-neuronal cells that regulate brain function in both normal and pathological conditions, accounting for about $10 \%$ of all non-neuronal cells within the CNS (1). Very recent studies have shown experimental evidence for altered social behavior in both rodents and humans when microglia is affected. Using a rodent model Kim et al (2) showed that deficient autophagy in microglia impairs synaptic pruning, alters connectivity between brain regions and causes social behavioral defects and repetitive behaviors, similar to those associated with autism spectrum disorders. Another study (3) demonstrated the importance of microglia for early life programming of juvenile and adult motivated behaviors. Neonatal microglia depletion led to reduced juvenile and adult anxiety behavior, increased locomotor activity, decreased juvenile social play and increased social avoidance behaviors in adults. Torres et al (4) described that local hippocampal depletion of microglia alters performance in tests of spatial memory and sociability, whereas a global depletion transiently altered spatial memory and produced no change in sociability behavior.

Received 22 November 2016, revised 7 December 2016, accepted 15 December 2016.

Correspondence to Dr Marin D. Zhelezov, Department of Anatomy, Histology and Embryology, Medical University, BG-9002 Varna, Bulgaria.E-mail: marin.zhelezov@gmail.com 
A recent study on human subjects (5) aimed at investigating if modulating microglia produces changes in social decision-making in healthy humans. 4-day oral administration of minocycline, a tetracycline antibiotic that can suppress microglial activation, sharpened participants' sense of trust and led them to be more decisive in in a trust game. The authors suggested that microglial activation may cause "unconscious noises" against appropriate social decision-making, and inhibiting microglial activity may reduce such noise (6). A subsequent trial (7) showed that in a trust game minocycline treatment shifts the main decision-modulating factor from cooperativeness to state anxiety and trustworthiness. The authors discuss that microglial suppression may lead to more situation-oriented decision-making by suppressing the effects of personality traits (6).

The results from the above studies suppose a possible microglial involvement in social behavior as causal agents. This paper aims at developing a hypothesis for a cellular mechanism, by which microglia may regulate the development and modulation of prosocial behavior and empathy.

\section{MICROGLIA IN CENTRAL NERVOUS SYSTEM MAINTENANCE AND DEVELOPMENT}

Under physiological conditions microglia possess multiple fine elongated processes that actively survey their cell-specific territory (8) and function as sentinels, detecting the slightest disturbance in homeostasis, tissue damage or pathogenic invasion. Because of these specific roles, microglia must be extremely efficient, sensitive to even the smallest damage to the CNS (9). As a response to pathological stimuli microglial cells transform into an activated amoeboid form that can perform phagocytic functions. Since under inflammatory conditions the risk to the CNS is high, microglia must, in addition, moderate tissue damage (10).

In the absence of pathology, the CNS hosts several myeloid cell populations, including perivascular, meningeal and choroid plexus macrophages, dendritic cells and microglia (11), thus researching the specific effects of these cells on the brain in health and disease can uncover fresh insights in the pathogenesis of CNS disorders and point to novel targets for medical intervention.

Microglia differ considerably from other tissue macrophages (12). A key difference lies in their origin: microglia are not derived from the bone marrow, as it was previously thought, but from primitive progenitors in the yolk sac that invade the brain very early in development when other glial cells are yet to be generated (13-15).

Microglia's early entry suggests a role in developmental processes in the CNS. Indeed, recently microglia have been shown to regulate the wiring of the embryonic forebrain by limiting the outgrowth of dopaminergic axons and affecting the laminar positioning of subsets of neocortical interneurons (16). Under physiological conditions microglia can enhance both neurogenesis and oligodendrogenesis in the early postnatal subventricular zone via released cytokines (17). Furthermore, microglia can control not only neuronal formation, but also differentiation and the formation, as well as, elimination of synapses (18-20). Postnatal synaptic pruning by microglial engulfment of synapses is key in the remodeling of neural circuits $(21,22)$.

In sum, microglia (i) play key roles in CNS physiology, and (ii) possess a large potential to either damage or repair the pre- and postnatal brain, which can be (iii) easily activated. Thus, microglia function on a continuum between sappers and repairmen.

\section{MICROGLIA AND EMPATHY: A HYPOTHESIS}

Regarding the relationship between microglia and prenatal CNS development, we can suppose the following sequence of events: (i) maternal immune activation, for example, due to infection leads to (ii) increase in inflammatory mediators which (iii) reach the fetus, (iv) activate microglia and ( $v$ ) change the developing brain. Current literature supports that the maternal immune response can elevate cytokine levels in the fetus (23) and epidemiological evidence suggests an association between maternal infection and neurodevelopmental abnormalities, including increased risk for developing schizophrenia and autism $(24,25)$. We can further suppose that microglial activation during postnatal brain development may interfere/change subsequent behaviors, which are produced and regulated by specific areas of the cortex.

Hypothesis: can microglia play a role in normal and pathological social behaviors, especially highly important ones such as empathy, compassion, altruism and moral reasoning by influencing the development of associated structures in the brain?

\section{WHAT IS EMPATHY}

Empathy is the ability to share others' emotions and exert cognitive control and perspective taking in our interactions (26) and includes cognitive empathy - using cognitive processes to understand and predict another's mental state, and affective empathy - the emotional response experienced as a 
consequence of another's state (27-30). Empathy and related responding, including caring and sympathetic concern, are considered crucial for moral reasoning, the motivation for prosocial behavior and inhibition of aggression (31).

The contemporary view stresses on the emerging of empathy and altruistic behaviors in early childhood. At 12 months of age infants will comfort others in distress, and only 2-6 months later will display spontaneous, unrewarded helping behaviors $(31,32)$. In addition, evidence suggests that the development of empathy and prosocial behavior is regulated by both genetic and environmental factors (33).

\section{EMPATHY, MICROGLIA AND THE BRAIN}

Considering microglia's known role in regulating the number of both neurons and synapses we can imagine a potential chain of events beginning with $(i)$ an obscure, clinically undetectable event that leads to (ii) a specific pre- and/or postnatal microglial activation that may (iii) lead to a disproportionally, regarding the primary event, large structural and functional deviation in the brain regions, involved in empathy and related behaviors, (iv) producing dramatic clinically-detectable symptoms.

We can consider two scenarios, where microglia is involved, that lie on a continuum:

(i) large deviations in empathy-related neuronal structure and function may lead to a profound alteration in behavior, that meets criteria for a clinical disorder, or

(ii) subtle changes in structure and function may lead to alterations in cognition and behavior that may remain clinically undetectable but, nevertheless, contribute to interindividual differences

The evidence, supporting the first scenario is large, coming mainly from investigating patients with medical disorders or brain lesions. Indeed, certain developmental disorders such as conduct disorder and disruptive behavior disorders are associated with impaired empathy and lack of remorse and guilt in affected children (34). In adults, lesions to the sensorimotor cortex impair affective empathy, whereas damage to the ventromedial prefrontal cortex (VMPFC) disrupts cognitive empathy (35). Furthermore, the VMPFC seems to play a role in moral decision-making. Lesions to the VMPFC are associated with increased endorsement of utilitarian responses to hard personal moral dilemmas (36-38).

The significance of the VMPFC becomes particularly apparent when studying patients with psychopathy. Psychopathy is a disorder, characterized by key disruptions in prosocial behavior, including shallow emotional responses, lack of empathy, impulsivity, and an increased likelihood for antisocial behavior (39-41). The involvement of the VMPFC in psychopathy has long been considered (36), but recent data stress on the diminished VMPFC connectivity as a robust neural correlate of the disorder (42).

Another study found that psychopathic individuals have nearly $10 \%$ increased striatum volume (43). Interpersonal and affective features of psychopathy were associated with caudate body volumes, whereas the impulsive, stimulation-seeking behavior correlated with caudate head volumes.

In light of the recent evidence for the developmental roles of microglia, it is not difficult to imagine a possible mechanism of microglial-specific alteration in the above mentioned structures and the subsequent behavioral consequences.

The second hypothetical scenario would not be easy to investigate due to difficulties in defining "normal" personality features and their "subtle" changes, and, at least, current technological limitations in identifying on a microscopic scale in vivo a causal link between microglia and neural function. Nevertheless, there is evidence that links individual differences in empathic abilities with observable differences in specific brain regions in normal, healthy subjects. One study (26) found that other-oriented empathy was negatively correlated with grey matter volume in the precuneus, inferior frontal gyrus, and anterior cingulate. In contrast, differences in selforiented affective empathy were positively correlated with grey matter volume in the insula and negatively correlated with somatosensory cortex volume. Furthermore, a positive correlation was found between grey matter volume in the anterior cingulate cortex and cognitive perspective-taking abilities. Grey matter changes in the right dorsolateral prefrontal cortex were positively related to the ability to empathise with fictional characters.

The correlation between individual differences in observable brain structures and abilities like empathy in normal, healthy subjects opens up the possibility for a microglial contribution in shaping the variety of our societal psychological landscape.

\section{CONCLUSION}

Recent research on microglia is characterized by frequent paradigm shifts: from simple macrophages to having unique origin and developmental role to, possibly, modulators of empathy and social behavior, microglial cells become ever more intriguing. With cells so potent to either repair or destroy, that "jump into action" to the smallest of sign, that 
can modulate the wiring of the brain, we may wonder, to what extent our most intimate aspect, our mind, has been and, maybe, continues being, sculpted by microglia. We can imagine how an obscure undetectable factor in our past may have, via a non-stochastic process, changed the behavior of our microglia and subsequently our own behavior as well. In order to progress, humanity needs to pass from the Information Age to the Compassion Age. Our present task is to stop wondering and start knowing what makes us good. Otherwise, our world will continue to suffer from moralom, a malignant tumor of the moral (44).

\section{REFERENCES}

1. Perry VH. A revised view of the central nervous system microenvironment and major histocompatibility complex class II antigen presentation. J Neuroimmunol 1998;90:113-121. DOI: 10.1016/S0165-5728(98)00145-3

2. Kim H-J, Cho M-H, Shim WH, Kim JK, Jeon E-Y, Kim $\mathrm{D}-\mathrm{H}$, et al. Deficient autophagy in microglia impairs synaptic pruning and causes social behavioral defects. Mol Psychiatry 2016. DOI: 10.1038/mp.2016.103.

3. Nelson LH, Lenz KM. Microglia depletion in early life programs persistent changes in social, mood-related, and locomotor behavior in male and female rats. $B e$ hav Brain Res 2017;316:279-293. DOI: 10.1016/j. bbr.2016.09.006.

4. Torres L, Danver J, Ji K, Miyauchi JT, Chen D, Anderson ME, et al. Dynamic microglial modulation of spatial learning and social behavior. Brain Behav Immun 2016; 55:6-16. DOI: 10.1016/j.bbi.2015.09.001.

5. Watabe, M., Kato, T. A., Monji, A., Horikawa, H., Kanba, $\mathrm{S}$. Does minocycline, an antibiotic with inhibitory effects on microglial activation, sharpen a sense of trust in social interaction? Psychopharmacology 2012; 220:551-557. DOI: $10.1007 / \mathrm{s} 00213-011-2509-8$

6. Kato TA, Kanba S. Are microglia minding us? Digging up the unconscious mind-brain relationship from a neuropsychoanalytic approach. Front Hum Neurosci 2013;7:13. DOI:10.3389/fnhum.2013.00013.

7. Kato, T. A., Watabe, M., Tsuboi, S., Ishikawa, K., Hashiya, K., Monji, A., et al. Minocycline modulates human social decision-making: possible impact of microglia on personality-oriented social behaviors. PLoS ONE 2012;7:e40461. DOI: 10.1371/journal.pone.0040461

8. Nimmerjahn A. Resting microglial cells are highly dynamic surveillants of brain parenchyma in vivo. Science
2005; 308:1314-1318. DOI:10.1126/science.1110647.

9. Dissing-Olesen L, Ladeby R, Nielsen HH, Toft-Hansen H, Dalmau I, Finsen B. Axonal lesion-induced microglial proliferation and microglial cluster formation in the mouse. Neuroscience 2007;149:112-122. DOI:10.1016/j. neuroscience.2007.06.037.

10. Wake H, Moorhouse AJ, Nabekura J. Functions of microglia in the central nervous system - beyond the immune response. Neuron Glia Biol 2011;7:47-53. DOI:10.1017/ S1740925X12000063.

11. Prinz M, Priller J. Microglia and brain macrophages in the molecular age: from origin to neuropsychiatric disease. Nat Rev Neurosci 2014;15:300-12. DOI: 10.1038/ nrn3722

12. Gautier EL, Shay T, Miller J, Greter M, Jakubzick C, Ivanov $\mathrm{S}$, et al. Gene-expression profiles and transcriptional regulatory pathways that underlie the identity and diversity of mouse tissue macrophages. Nat Immunol 2012; 13:1118-1128. DOI:10.1038/ni.2419.

13. Alliot F, Godin I, Pessac B. Microglia derive from progenitors, originating from the yolk sac, and which proliferate in the brain. Dev Brain Res 1999; 117:145-152. DOI: 10.1016/S0165-3806(99)00113-3

14. Chan WY, Kohsaka S, Rezaie P. The origin and cell lineage of microglia - New concepts. Brain Res Rev 2007; 53:344-354. DOI:10.1016/j.brainresrev.2006.11.002.

15. Ginhoux F, Lim S, Hoeffel G, Low D, Huber T. Origin and differentiation of microglia. Front Cell Neurosci 2013;7. DOI:10.3389/fncel.2013.00045.

16. Squarzoni P, Oller G, Hoeffel G, Pont-Lezica L, Rostaing $\mathrm{P}$, Low D, et al. Microglia Modulate Wiring of the Embryonic Forebrain. Cell Rep 2014;8:1271-9. DOI:10.1016/j. celrep.2014.07.042.

17. Shigemoto-Mogami Y, Hoshikawa K, Goldman JE, Sekino Y, Sato K. Microglia Enhance neurogenesis and oligodendrogenesis in the early postnatal subventricular zone. J Neurosci 2014; 34:2231-2243. DOI:10.1523/ JNEUROSCI.1619-13.2014.

18. Tremblay M-È, Lowery RL, Majewska AK. Microglial Interactions with Synapses Are modulated by visual experience. PLoS Biol 2010;8:e1000527. DOI:10.1371/journal. pbio. 1000527.

19. Graeber MB. Changing face of microglia. Science 2010;330:783-788. DOI: 10.1126/science.1190929.

20. Hughes V, et al. The constant gardeners. Nature 2012;485:570-572. DOI: 10.1038/485570a 
21. Paolicelli RC, Bolasco G, Pagani F, Maggi L, Scianni M, Panzanelli P, et al. Synaptic Pruning by Microglia Is Necessary for Normal Brain Development. Science 2011;333:1456-8. DOI:10.1126/science.1202529.

22. Schafer DP, Lehrman EK, Kautzman AG, Koyama R, Mardinly AR, Yamasaki R, et al. Microglia Sculpt Postnatal Neural Circuits in an Activity and ComplementDependent Manner. Neuron. 2012;74:691-705.

23. Goepfert AR, Andrews WW, Carlo W, Ramsey PS, Cliver SP, Goldenberg RL, et al. Umbilical cord plasma interleukin-6 concentrations in preterm infants and risk of neonatal morbidity. Am J Obstet Gynecol 2004; 191:1375-1381. DOI:10.1016/j.ajog.2004.06.086.

24. Ellman LM, Susser ES. The promise of epidemiologic studies: Neuroimmune mechanisms in the etiologies of brain disorders. Neuron 2009; 64:25-27. DOI: 10.1016/j. neuron.2009.09.024.

25. Harry GJ, Kraft AD. Microglia in the developing brain: A potential target with lifetime effects. NeuroToxicology 2012; 33:191-206. DOI:10.1016/j.neuro.2012.01.012.

26. Banissy MJ, Kanai R, Walsh V, Rees G. Inter-individual differences in empathy are reflected in human brain structure. NeuroImage 2012;62:2034-9. DOI:10.1016/j. neuroimage.2012.05.081.

27. Preston SD, De Waal FB, et al. Empathy: Its ultimate and proximate bases. Behav Brain Sci 2002; 25:1-20. DOI: 10.1017/S0140525X0247001X

28. Baron-Cohen S, Wheelwright S. The empathy quotient: an investigation of adults with Asperger syndrome or high functioning autism, and normal sex differences. $J$ Autism Dev Disord 2004;34:163-175. DOI: 10.1023/B:J ADD.0000022607.19833.00

29. Decety J. The functional architecture of human empathy. Behav Cogn Neurosci Rev 2004; 3:71-100. DOI:10.1177/1534582304267187.

30. Batson C.D. These things called empathy: eight related but distinct phenomena. In: Decety J, Ickes WJ, editors. The Social Neuroscience of Empathy. MIT Press, Cambridge, MA. 2009.

31. Eisenberg N, Eggum ND. Empathic responding: sympathy and personal distress. In: Decety J, Ickes W, editors. The Social Neuroscience of Empathy. MIT Press, Cambridge: 2009. pp. 71-83.

32. Decety J. The neurodevelopment of empathy in humans. DevNeurosci 2010; 32:257-267. DOI:10.1159/000317771.

33. Knafo A, Zahn-Waxler C, Van Hulle C, Robinson JL, Rhee $\mathrm{SH}$. The developmental origins of a disposition toward empathy: Genetic and environmental contributions. Emotion 2008; 8:737-752. DOI: 10.1037/a0014179.

34. Dewied M, Vanboxtel A, Zaalberg R, Goudena P, Matthys W. Facial EMG responses to dynamic emotional facial expressions in boys with disruptive behavior disorders. J Psychiatr Res 2006; 40:112-121. DOI: 10.1016/j.jpsychires.2005.08.003.

35. Shamay-Tsoory SG, Aharon-Peretz J, Perry D. Two systems for empathy: a double dissociation between emotional and cognitive empathy in inferior frontal gyrus versus ventromedial prefrontal lesions. Brain 2009; 132:617-627. DOI:10.1093/brain/awn279.

36. Koenigs M, Young L, Adolphs R, Tranel D, Cushman F, Hauser M, et al. Damage to the prefrontal cortex increases utilitarian moral judgements. Nature 2007; 446:908-911. DOI: 10.1038/nature05631

37. Prehn K, Wartenburger I, Mériau K, Scheibe C, Goodenough OR, Villringer A, et al. Individual differences in moral judgment competence influence neural correlates of socio-normative judgments. Soc Cogn Affect Neurosci 2008; 3:33-46. DOI:10.1093/scan/nsm037.

38. Pascual L, Rodrigues P, Gallardo-Pujol D. How does morality work in the brain? A functional and structural perspective of moral behavior. Front Integr Neurosci 2013;7. DOI:10.3389/fnint.2013.00065.

39. Cleckley HM. The mask of sanity: an attempt to clarify some issues about the so-called psychopathic personality. Augusta, Georgia. E.S. Cleckley. 1988.

40. Hare RD. Psychopathy: A clinical construct whose time has come. Crim Justice Behav 1996; 23:25-54. DOI:10. 1177/0093854896023001004.

41. Anderson NE, Kiehl KA. Psychopathy: Developmental perspectives and their implications for treatment. Restor Neurol Neurosci 2014; 32:103-117. DOI: 10.3233/RNN139001.

42. Motzkin JC, Newman JP, Kiehl KA, Koenigs M. Reduced prefrontal connectivity in psychopathy. $J \mathrm{Neu}$ rosci 2011;31:17348-17357. DOI: 10.1523/JNEUROSCI.4215-11.2011.

43. Glenn AL, Raine A, Yaralian PS, Yang Y. Increased volume of the striatum in psychopathic individuals. Biol Psychiatry 2010; 67:52-58. DOI:10.1016/j.biopsych.2009.06.018.

44. Chaldakov GN. Quo vadis, Europa? In: Homo Janus Bulgaricus. Psychology and Pathopsychology (not only) of Bulgarians. Publissays and science-in-fiction. MS-Varna Publisher. 2016. pp 209-214. 